\title{
Marketers' expanded role to increase internal customer satisfaction in organizational change
}

\author{
Adina ROTILEANU \\ The Bucharest University of Economic Studies, Bucharest, Romania \\ arotilea@nyit.edu
}

\begin{abstract}
During times of change, when companies are going through major transformations like mergers, acquisitions, organizational re-structuring or culture change, marketing faces the challenge to implement the new strategy as scheduled, with no delays or changes. Internal customer change acceptance plays a significant role in this endeavor and marketers need to expand their role and complement Human Resources strategy to building trust between decision makers and employees, to learn and understand past issues and to find solutions. In this circumstance, marketers' have to identify the variables that generally influence internal customer satisfaction and develop them in marketing tools aimed to increase it to the level that strategy is accepted and implemented faster than using only Human Resources mechanisms. This paper is a result of marketing practice in medium and large companies that went through organizational change. The goal of this case study is to create, based on time, discipline and cross-functional skills variables, a model of efficient processes and evaluation of marketing actions that will increase employees' trust in change management decisions and will lead to their support and engagement.

The three independent variables allowed researcher to study the complex relationship between internal client satisfaction phenomena, organizational change context and thirty-six crossfunctional employees including management, ultimately to answer how these variables can be used by marketers to get the internal customer change buy-in. The research showed that the new developed marketing tools, that is to say a process flow associated with sustainable procedures and Service Level Agreements, increased internal customer satisfaction and contributed to smooth and consistent marketing strategy implementation, as scheduled. This result means the theory that marketers role in times of organizational change, besides regular Key Performance Indicators regarding the external client, expanded to complement Human Resources towards increasing internal customer satisfaction, determines a faster change acceptance, was validated.
\end{abstract}

Keywords: marketers, internal client satisfaction, organizational change, process flow, procedures, Service Level Agreement.

\section{Introduction}

The marketer's success in an organization is the organization success in the market. The market share, customer satisfaction, returned customers are just few of the indicators taken into consideration when evaluating success. To reach high-level performance indicators, marketers need to look at competition, product features and benefits, distribution and promotional channels, price and to very closely analyze their dynamics on short and long term to be able to design an effective marketing strategy. Crossfunctional projects gather together people from various other departments besides Marketing for the same common purpose, from launching a new product to reaching new customers segments.

When business runs in a stable organizational environment, the marketers' role implies teamwork outside and within marketing department, clear responsibilities and performance indicators for each team member, with HR department involvement.

However, when change occurs at organizational level, the disruption can be translated from daily activity change to lack of trust and resistance to change management, which leads to employee dissatisfaction. Marketing is responsible to communicate the change to all stakeholders and the internal dissatisfaction affects its 
activity. HR departments use various resources to prepare and train people to cope with change yet the marketers' activity is under a lot of scrutiny. Moreover, many of the previous interdepartmental issues are now inquired under the suspicion that something done in the past could have determined the (unwanted) change. To solve these issues will take management and HR time, discipline and cross-functional skills development. By the time these are implemented, the marketing strategy execution will be delayed, changed several times to accommodate the internal client comments and eventually, the external customer will be provided with no coherence.

For that reason, in addition to HR strategy, marketers should expand their role to facilitate a faster change acceptance. Consequently, how can they use the above mentioned independent variables to answer in an efficient way to internal concerns, to increase the internal client trust and get the buy-in for the actual strategy?

The experiment ran on a group of people in times of organizational change aimed to develop new tools related to time, discipline and cross-functional skills, such as process flow, procedures and Service Level Agreements and to study how these new independent variables were related to internal client satisfaction.

If the new marketing tools helped increasing internal client satisfaction, the marketing strategy will get the internal client support for smooth and consistent implementation faster than using only HR mechanism.

The long-term goal is to validate the case study results in other organizational change contexts, with the same participants distribution, further investigating the complex relationship between marketers' role and internal client satisfaction.

This paper will provide a model of efficient processes and marketing actions evaluation, created in times of organizational change, that increased employees' trust in change management decisions and led to their support and engagement.

\section{Literature review}

The organizations, regardless their size or industry, strive for more and happier customers who in return, bring them higher profits. Landry, Ripsam, \& Kapoor (2011) mentioned in their work that from an organizational perspective, different roles for business units, corporate, marketing need to be clearly defined when opting for shared services for HR, Marketing or IT departments, with the purpose to align the employees behavior to organizational culture, values and brand communication. When changes occur, this becomes harder to implement and an intra-departmental hub, namely internal marketing, becomes a priority.

About 2 decades ago the concept of 'shared services' has been introduced to centralize and consolidate the activities in one location but also to run marketing activities as a business, to deliver high quality services at an appropriate cost and in a competitive timeframe to internal customers.

According to Zeithaml, Bitner, \& Gremler (2010) in relation with customer satisfaction, this is slightly differently approached in goods marketing as compared to services marketing. For instance, in services marketing, the 4Ps (Kotler \& Armstrong, 2010) are only partially adequate for an effective service marketing strategy because the focus is on the customer usage and relationships, on customer service. The $5^{\text {thP }}$ (people) becomes a critical point for managers who realize how important the employee satisfaction has become in improving customer satisfaction. In other words, an unsatisfied employee can lead to multiple unsatisfied customers that are hard to identify (Donnelly, 1999). 
When change occurs in an organization, whether is about re-branding, restructuring or paradigm shift, marketing role is expanding to complement HR and management in communicating and implementing the changes inside the company hence internal marketing, targeted towards internal client, becomes far-reaching. Internal communication has impact on employees' development, in managers rethinking their teams roles and processes, for this reason internal marketing is defined by some scholars as a human resource management function (Rafiq, Ahmed, \& Pervaiz, 1993). As a matter of fact all managers need to improve their communication skills to 'marketing' the benefits of the organizational change that entails important transformations for employees (Owens \& Hyatt, 2015).

Dunne, Barnes, Lewis, \& Varey (2000) mentioned that when crises or any organizational change takes place, marketers' first costumer is internal client who has to buy-in the implementation plan before this is made known to external customer.

\section{Internal Client $=$ Employees}

As observed by Bruhn in (Munteanu, Pagalea, \& Cristea, 2014), personnel motivation and satisfaction are major objectives for internal marketing plan. While the employees were segmented based on work related motivation and attitudes in 6 types, from survivors to addicts, 2 measures were identified for internal customer satisfaction: personal service and technical competence (Gilbert \& Gilbert, 2006).

To be able to create the framework for the expanded marketing role in times of change and towards increasing internal client change awareness and support, marketers need to outperform their personal service, to understand motivation and where they want to get. This takes time, discipline and cross-functional skills (Kugel, 2015) and once the employees understand what the change implies, they are involved, enabled and satisfied (Schmalensee, 1991).

\section{Time $=$ Process}

Time is a scarce resource. In practice, process driven actions and procedures avoided the time loss and concentrated the energy in efficient way. In the same time, processes offered the opportunity to 'begin with the end' in mind (Covey, 2004) and to build carefully the steps to reach the agreed objectives, both on regular basis and when change occurs. It also refers to patience and consistency of actions for a certain period of time needed to build differentiation or any type of added value [Patience and differentiation have been mentioned by the author in an interview in 2011 (http://www.smark.ro/articol/21013/rabdare-bugete-si-diferentiere-trei-cuvinte-la-moda-inasigurari)].

According to (Covey, 2004) time management matrix of urgent versus not urgent and important versus not important activities, the daily marketing activities are directed to being more in third quadrant (urgent ones, important only for certain individuals, solved with priority) then long-term effective, to satisfy internal customer demand, especially in services providing companies. When the wind of change blows, the management board has certain objectives that are translated in disruptive measures and the two conventional strategy practices are challenged. The created discontinuities (Dru, 1996) may be translated in innovation in terms of product, distribution channels, brand and processes, that means in focusing on effectiveness. 


\section{Discipline $=$ Procedures}

Discipline implies both knowing and understanding the organization, its goals, strategies and consumers, also to have the capability to saying 'no' if certain things, from various reasons such as lack of appropriate knowledge, cannot be delivered (Carter, 2014). The step-by-step procedure development offered discipline providing the templates and needed resources for marketing activities to be performed.

Marketing science is using quantitative and qualitative reports to assess the business and marketers performance. The common KPIs are measurable in terms of customer satisfaction, customer retention, average ticket size or web traffic, to mention just a few. Yet, there are qualitative aspects, such as procedures, that are subjective and cannot be measured in terms of value and percentages but rather interpreting them in context and "to incorporate the results of a 'key' validation" (Cătoiu \& Teodorescu, 2004).

\section{Cross-functional skills - Service Level Agreements}

While Key Performance Indicators are specifically developed for each department, cross-functional skills involve learning and understanding front and back offices needs and finding the best solution to address them (Owens \& Hyatt, 2015).

To avoid subjectivity in terms of internal customer satisfaction, formal service level agreements should be developed. Their purpose is to ensure a consistent quality standard regardless of the department or individual involved in the project and to help matching the deliverables with the objectives (Carter, 2014).

\section{Research methodology}

The research presented in this paper has been conducted when the organization name, structure, internal culture and customer approach were changed, after more than 10 years of activity in a highly competitive market. Many high performance employees were working in the company from the beginning, consequently, very much used to the Status Quo and the reasons behind all these changes were not clear or easily accepted.

\section{Hypothesis}

The marketers' duties in this organization before change were to develop and implement marketing activities based on internal customer requests. Their mission after the change was to develop and implement marketing strategy in line with the changed company strategy, to reach indicators such as brand awareness, market share and customer satisfaction. Lack of mitigation measures could easily predict the internal client dissatisfaction that will affect strategy implementation and the coherence provided to external customer.

If new marketing tools development and usage raise internal client satisfaction, then, developing and using these tools, the marketing strategy will get the internal client support for smooth and consistent implementation faster than using only $\mathrm{HR}$ mechanism - that concluded few months later, after many trainings.

\section{Research Procedure}

'Trust' had to be investigated, what caused the lack of trust and how this can be mitigated. Past experience had shown there were unresolved issues between internal clients and marketing therefore, discussion on this topic were needed. Individual meetings with managers were planned to find out the issues raised prior change occurrence and to understand why they were unresolved yet. To set up a clean arena for 
the new communication, this was the learning phase of various obstacles or crossfunctional disputes and was based on few simple questions: what didn't work, why do you think it didn't work, how do you think it may work. Questions - answers dichotomy in an organization can be vast, consequently they were limited to those related to interdepartmental questions, specifically between marketing department and internal client.

Once these issues were acknowledged and all insights analyzed, some time was spend to figure out possible solutions. These were again discussed, debated and eventually agreed with the participants.

All ideas and insights were integrated and the results were inter-departmental shared as best practice.

\section{Participants}

The study participants consisted of 8 marketers, 2 for each activity category as they appear in the process flow (Figure 2) and 28 people from 9 departments including management board as in Figure 1. The number of people in the study was not proportional with the department size as for activities related to IT, graphic design or research, external companies were solicited, however, it took into consideration the business two-fold structure.

The selected people were the marketing contact point and participating in crossfunctional projects. They were usually either more demanding (in sales) or critical to any change (operations).

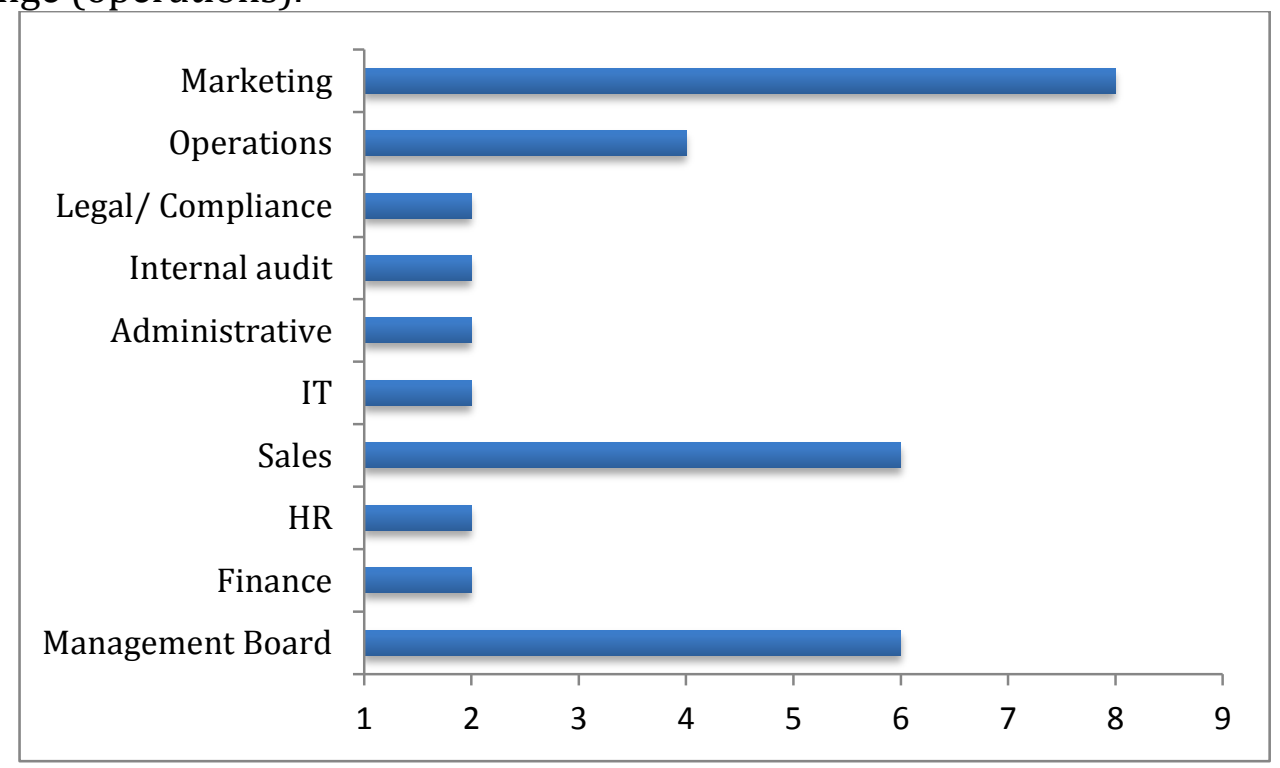

Figure 1. Inter-departmental participants distribution

Source: Author's own research.

\section{Materials}

Computer programs were used in this study such as Microsoft Outlook, Word, Excel and Visio.

\section{Other details}

The research started as an experiment to examine marketers' ability to use the 3 variables in times of organizational change when they are under tight deadlines to implement the strategy and developed into this instrumental case study on a small group of subjects who were examined during several years of working practice. This presents "real-life situations", useful insights of the subjects and may further allow 
generalization for larger groups [The limitation in case studies as defined by (Fletcher et al., 1997) is the lack of results generalization]. The practical experience provided a reference point in studying the complex relationship between the internal client satisfaction, organizational change and people from 9 departments plus management.

\section{Results}

Organizational vicissitudes offered marketers the opportunity to come up with answers for questions occurred in front and back offices that were related to 'time' as absence of processes, to 'discipline' as scarcity of procedures and to 'cross-functional skills' as lack of consistent quality and measurement against the objectives. Together with the knowledge to optimize and to make the sound choice between having in house activities or outsourcing them - as graphic design, PR, website - marketers were qualified to build trust bridges with internal client faster and the marketing strategy was implemented with no delays or changes.

The variable 'time' was translated into the process flow. The usefulness of the process is linked not only to the marketing department but also to other departments, creating a framework to building internal client trust.

Asking questions, from why to how and when, most of them related to marketing functions responsibilities and needed approvals, identified the issues diagnoses source. The next step was to analyze the questions, to group them in a process flow (Figure 2) and agree on an answer, on a solution that, from resources (time, people and budget) perspectives, was feasible.

There were identified two types of solutions:

1. Procedures to create discipline, to have a common understanding and upfront agreement on why some projects or activities cannot be performed or what resources are needed to deliver a good inter-departmental project.

2. Service Level Agreements to create cross-functional skills, to have a common understanding and agreement on what a good inter-departmental project is, to match the project deliverables with the objectives.

These solutions were eventually integrated in a Questions \& Answers document where all employees had access.

Once this agreed, the change communication followed the same path, both inter and intra-departmental. 


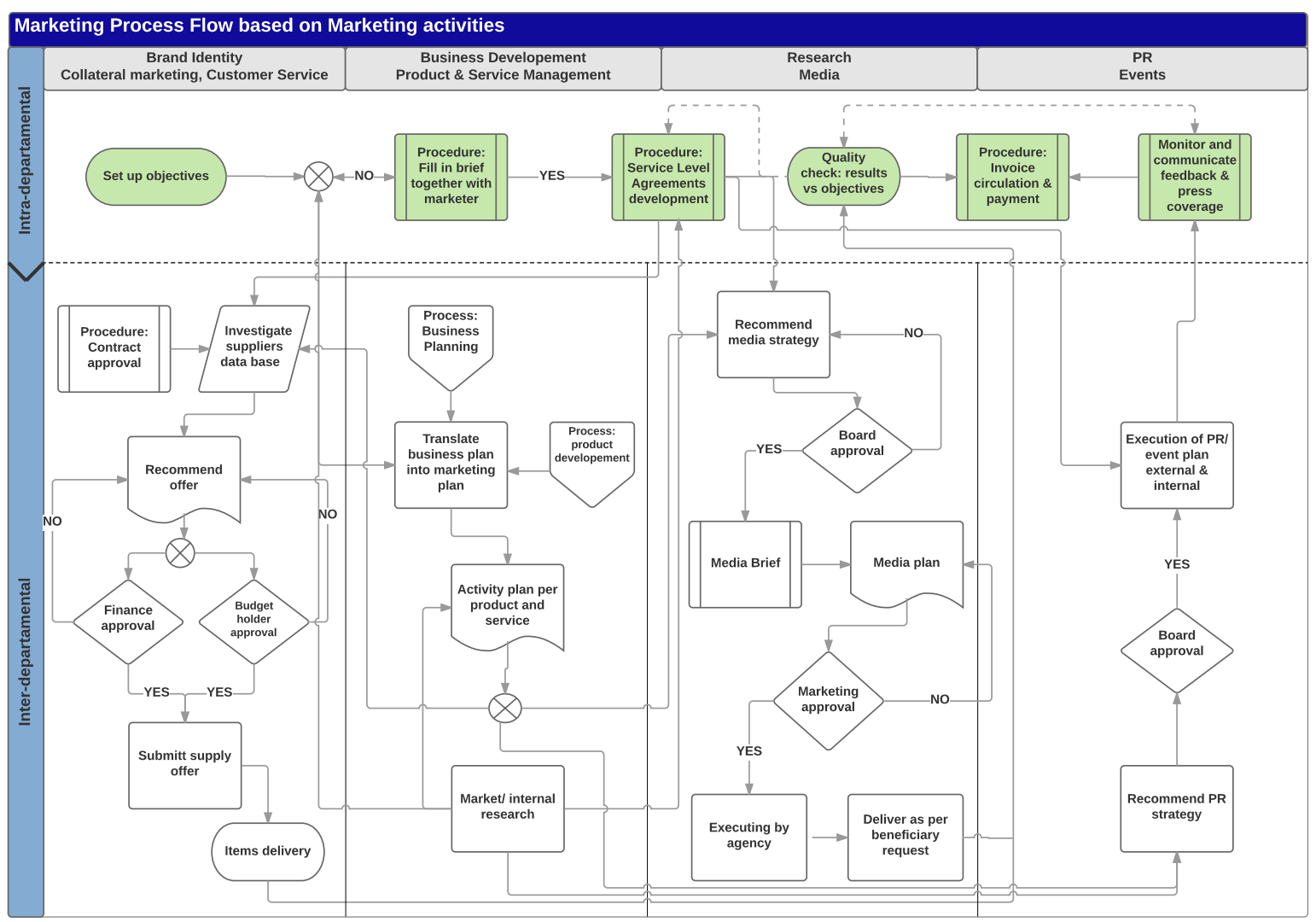

PICBE | 460

Figure 2. Marketing process flow

Source: Author's own research.

Let's take for instance how process flow, procedures and SLAs were developed for one important and challenging activity - events organization to communicate change (The discussed situations are outside the planned and marketing driven organizational events but at internal client initiative). Whether inter-departmental or cross-functional gathering as team buildings or client events, controversial discussions and arguments were always before and after the event, regarding the quality of the event. This was proven to be a subjective matter, the decision to organize event was without appropriate briefing, emotionally and hasty taken.

The intra-departmental process flow, color highlighted in Figure 2, started from overall marketing objectives based on which the Business Development marketers created the briefing form template to be filled in together with the beneficiaries, namely with the internal clients involved. If the brief didn't fit the objectives, the marketers would recommend internal client a different approach, starting from market research results. The Events marketers organized the event, monitored the participants' feedback and press coverage and send the report to Research for reference and for payment. Also, SLAs screening was performed based on the results.

The brief template fill in procedure included questions and answers regarding why was the event needed, what was its purpose, what are the expected results and how the results can be evaluated. For quality assessment, SLAs, further highlighted in italic, were developed and agreed.

Words such as 'quickly', 'nice', 'many', 'fresh', 'subject matter', 'interesting' were largely used and the marketers perspective of this features was different from sales, operations or HR perspective that led to all parties dissatisfaction.

Consequently, communicating change to our most top 100 important partners replaced 'increasing awareness' - that was too broad and linked to so many other activities, very 
difficult to determine - expected number of participants would replace 'many' or 'more than last time', positive feedback forms or, if the case be, the post event media coverage would replace 'interesting', specialist guest speaker names would replace 'subject matter'.

The 'quickly', one of the most debated features, was replaced by number of days or weeks and the event date had to be set up at least 5 weeks prior to the first possible event date, to make sure the locations are available and no other similar events are in the same time.

'Nice' location and 'fresh' decoration became easier to agree upon as soon as Brand Identity marketers were involved in discussion. Based on the allocated budget, available time and brand guidelines, marketers recommended potential places and decorations.

All procedures and SLAs presented in the process flow were developed following the same pattern and became the deliverables match objectives blueprint for the actual and future employees interacting with marketing department.

\section{Conclusion}

The literature review confirms that any change in organization is a sensible matter that needs to be carefully planned and implemented. As this course takes time, discipline and cross-functional skills, marketers are eligible to expand their role and engage in the process along with HR for faster change acceptance. Furthermore, internal client communication and satisfaction becomes a prerogative to ensure change strategy implementation for external customer satisfaction greatest goal.

To get the internal client change acknowledgment and strategy buy-in, marketers used the independent variables to provide new, customized marketing solutions. The case study presented in this paper provided deductive reasoning that developing and implementing new marketing tools in times of organizational change increased the internal client trust that contributed to smooth and consistent marketing strategy implementation, with no delays.

Internal client was involved from the beginning in designing the communication flow, misunderstanding could have been fixed and process flow has been developed together with participants from other departments. This allowed developing common and more practical language to send information across departments and functions.

The solutions were translated in a marketing communication process flow and a sustainable assemblage of procedures and Service Level Agreements, internally validated through marketing strategy implementation as scheduled.

The procedures and the SLAs included in the process flow clarified all the information about who has to do, what and when, to have a high quality cross-functional action. The post evaluation became objective and the goal achievement simple to assess. Even when the outcomes were not too good, the internal client satisfaction was high because it knew when and why it went wrong and made room for further improvements.

At a first sight it may seem a bureaucratic approach and too much time spent formalizing actions, yet, the outcome of this research is that the organizational change offered a good opportunity for marketers to expand their regular role and find effective solutions for better inter-departmental communication and cross-functional results, for faster change acceptance.

The process flow together with several procedures and Service Level Agreements for cross-functional activities were further used and expanded in another organization 
based on specific change criteria to test their external validity and to study if any extraneous variable may affect the results.

The main contribution of this case study is introducing the theory that marketers expanded role in times of organizational changes to complement HR department for faster change acceptance is to develop customized marketing tools, namely process flow, procedures and SLAs, that are linked one to another and that influence internal client satisfaction.

The limitation however stands in the variety of processes and SLAs that can be developed based on the company structure, the type of change, product portfolio and life cycle stage. SLAs were developed during organizational change and successfully used for less than 5 years therefore this research doesn't cover their long-term internal validity when control variables, such as number of participants from marketing department, may differ. Also, some of them were tested and validated in another organization, with a different type of change and structure, and few more were added. As all the insights in this case study were collected based on effective work in a company and not based on questionnaires or interviews, a research to further validate the findings will be planned based on the work environment opportunities.

\section{References}

Carter, D. (2014). The power of "know" and "no" in effective customer service delivery. Business Information Review, 31(3), 160-165. https://doi.org/10.1177/0266382114552045.

Cătoiu, I., \& Teodorescu, N. (2004). Comportamentul Consumatorului (2nd ed.). Bucharest: Uranus.

Covey, S. R. (2004). The 7 Habits of Highly Effective People Powerful Lessons in Personal Change. New York: Simon \& Schuster.

Donnelly, J. H. (1999). Another Look at Customer Satisfaction. Bank Marketing, 31(11), 44.

Dru, J.-M. (1996). Disruption: overturning conventions and shaking up the marketplace. New York: John Wiley \& Sons.

Dunne, P. A., Barnes, J. G., Lewis, B., \& Varey, R. (2000). Part IV: Communication and Service Delivery: Chapter12: Internal Marketing: A relationships and valuecreation view. Internal Marketing: Directions for Management, (Im), 192-220.

Fletcher, R. H., Fletcher, S. W., Jiménez, V., Díaz De Salas, S., Mendoza, V., Porras, C., ... Noor, K. B. M. (1997). Case study as a research method. Academy of Management Review, 5(2), 301-316. https://doi.org/10.1177/15222302004003007.

Gilbert, G. R., \& Gilbert, G. R. (2006). Research and concepts Measuring internal customer satisfaction. Managing Service Quality: An International Journal, 10(3), 178-186. https://doi.org/http://dx.doi.org/10.1108/09604520010336704.

Kotler, P., \& Armstrong, G. (2010). Principles of marketing (13th ed.). Upper Saddle River, NJ: Prentice Hall.

Kugel, C. (2015). the Metrics Map: Using Analytics To Navigate Metrics of Substance Versus Metrics of Convenience. Marketing Insights, 27(1), 30-34.

Landry, E. C., Ripsam, T., \& Kapoor, N. (2011). Shared services in marketing organizations. Retrieved from http://www.strategyand.pwc.com/media/file/Shared-servicesin-marketing-organizations.pdf.

Munteanu, C., Pagalea, A., \& Cristea, A. (2014). A holistic approach on internal marketing implementation. Business Management Dynamics, 3(11), 9-17. https://doi.org/10.13140/2.1.1790.0163. 
Owens, D. W., \& Hyatt, J. (2015). No End to Change. CFO Magazine, November, 107-123. Retrieved from http://ww2.cfo.com/operations/2015/11/no-end-change/.

Rafiq, M., Ahmed, P. K., \& Pervaiz, K. (1993). The scope of internal marketing: Defining the boundary between marketing and human resource management. Journal of Marketing $\quad$ Management, 219-232. https://doi.org/10.1080/0267257X.1993.9964234.

Schmalensee, D. (1991). Internal Customer Satisfaction. Managing Service Quality: An International Journal, $1(3)$ 141-144. https://doi.org/http://dx.doi.org/10.1108/EUM0000000003138.

Zeithaml, V. a., Bitner, M. J., \& Gremler, D. D. (2010). Services marketing strategy. Wiley International Encyclopedia of Marketing Part 1: Marketing Strategy, 1(May), 208218. https://doi.org/10.1002/9781444316568.wiem01055. 